\title{
Study on Treatment and Management of Ileal Perforation
}

\author{
Dr. Binay Kumar ${ }^{1}$, Dr. D. K. Sinha ${ }^{2}$, Dr. Manoj Kumar ${ }^{3}$ \\ ${ }^{1}$ Assistant Professor, Department of General Surgery, RIMS Ranchi, Jharkhand, India \\ ${ }^{2}$ Associate Professor, Department of General Surgery, RIMS Ranchi, Jharkhand, India \\ ${ }^{3}$ Junor Resident, Department of General Surgery, RIMS Ranchi, Jharkhand, India
}

\begin{abstract}
Objective: Our aim was to study the different surgical treatment done in patients with ileal perforation admitted in RIMS, Ranchi, and a centre of excellence in Jharkhand, India. Methods: This is a prospective observational study of patients operated for ileal perforation in a year. A total of 70 patients were evaluated. Their age, sex, signs, symptoms, lab investigations, their general status, operative interventions, and post-operative morbidity and mortality recorded. Results: Out of 70 patients, $60 \%$ were due to typhoid, $20 \%$ were due to trauma, rest others included tubercular (13\%) and 7\% whose cause couldn't be ascertained. The surgical procedu re performed were primary ileostomy in 57 patients, simple closure in 8 patients, resection and anastomosis in 2 patients and simple closure followed by defunctioning loop ileostomy in 3 patients. Conclusion: Appropriate and apt surgical procedure should be based on patients' general condition, time since presentation and operative findings. Timely and appropriate surgical intervention decreases morbidity and mortality.
\end{abstract}

Keywords: ileal perforation, ileostomy, trauma, surgery, RIMS

\section{Introduction}

Correct and timely interpretation of acute abdomen is one of the most challenging demands in developing countries where medical facilities are not readily available. Ileal perforation is one the most common cause of acute abdomen, which is a surgical emergency. Causes include enteric fever, tuberculosis, trauma besides Meckel'sdiverticulum, parasitic infestations etc. Delay in surgical procedures occurs due to delayed reporting of patients in hospitals. The other factors that determined surgical procedure were age, anemia, hypovolumic shock, contamination of peritoneum[1]. Surgical options were primary closure, resection and anastomosis, primary closure with defunctioning proximal loop ileostomy and primary ileostomy.

The primary objective was to evaluate different options available to minimise patients morbidity and mortality.

\section{Methods}

This was a prospective observational study for one year. All patients received written informed consent and the study was approved by the institutional ethical committee. Detailed history was taken and thorough examination was done. Demographic profile, clinical features, blood investigations, $\mathrm{x}$ ray chest and abdomen erect were all collected. Widal test was done in suspicious patients. Initial approach was focussed on resuscitation of the patient by intravenous fluids, electrolytes correction, broad spectrum antibiotics. Once the patient was stabilised, they underwent exploratory laparotomy. Decision regarding type of surgical procedure was decided on the table, depending on the intraoperative findings keeping other factors in mind. A thorough peritoneal lavage with 2 to 3 litres of warm normal saline was done followed by placing an intra-peritoneal drains in pelvis. Patients were followed post-operatively with administration of broad spectrum and appropriate antibiotics, were kept nil orally till bowel movements were present. They were looked for post-operative complications such as wound dehiscence, wound infection, burst abdomen or anastomotic leak. Biopsy was taken to know the cause of perforation.

\section{Results}

70 cases of non-traumatic and traumatic ileal perforations were followed during the study period of which typhoidal perforation cases were $42(60 \%)$, tubercular $8(13 \%)$, idiopathic $6(7 \%)$ and traumatic perforation amounted to 14 cases $(20 \%)$ as in Table 1 . Bar graph 2 shows that 26 cases of perforation reported between 25 to 48 hours after onset of illness while 20 patients reported in the initial 24 hours, 15 cases reported after 48 hours while 9 cases reported even after 72 hours. Thus majority of patients reported late in hospital. Bar graph 2shows that abdominal pain was present in almost all the 54 cases where as vomiting, fever and stoppage of flatus and faeces were present 44,37 and 44 cases of perforation respectively. Bar graph 4shows that abdominal tenderness was found in 70 cases $(100 \%)$, guarding and rigidity in 65 cases $(93 \%)$, abdominal distension in $38(54 \%)$, obliteration of liver dullness was present in 43 cases (61\%). Radiological evidence of free gas under diaphragm was found in 52 cases $(75 \%)$ majority is under right side, multiple fluid levels in 30 cases $(42 \%)$ while the findings were inconclusive in 10 cases $(14 \%)$ as in Pie graph 1.

All cases were managed by surgically. Surgical interventions were divided into four types.(Pie chart 2)

1) Simple closure in two layers- in 8 patients. Anastomotic leak was observed in two patients for which proximal ileostomy was done in re-exploration. Patients, however, survived. 


\section{International Journal of Science and Research (IJSR) \\ ISSN (Online): 2319-7064}

Index Copernicus Value (2015): 78.96 | Impact Factor (2015): 6.391

2) Resection and anastomosis- in 2 patients. There was no leak from anastomotic site. One patient had wound site infection .

3) Simple closure followed by defunctioning proximal loop ileostomy- in 3 patients

4) Primary ileostomy followed by closure in 6-12 weeks in 57 patients. Out of these 4 patients couldn't survive. On analysis of these patients, patients' age, delay in presentation and general condition of the patient was found to be the major prognostic conditions.

Pie graph 3 shows that wound infection was found in 4 cases $(6 \%)$, wound dehiscence in 4 cases $(6 \%)$, burst abdomen in 3 cases $(4.2 \%)$ and leak from either primary closure or resection and anastomosis in 5 cases. Hospital stay was 6 to 10 days in 56 cases, 11 to 15 days in 15 cases and even higher in 3 cases. Most of the patients stayed in hospital for about 10 to 14 days.6\%patients who stayed for more than due to some sort of complications. Mortality was maximum in the age group of 41 years.

Terminal ileum was the most common site of perforation.

\section{Discussion}

Ileal perforation is a common cause of peritonitis and it presents as a diagnostic dilemma to the surgeon. The mean age in our study was higher as the children below 15 years were excluded. The clinical features were similar to any other acute abdomen and decision for laparotomy was taken on clinical grounds complimented by radiological images. The delay in surgery was mainly due to delayed referral from remote areas where medical facilities are scarce or no transportation facility.

Typhoid fever is noted as a serious health problem by WHO[2]. The enteric fever,is probably the most common cause of perforations of ileum, ranging upto 78\%[3]. There is male preponderance in typhoid perforation[4,5]. Tubercular perforation seem to be under diagnosed [6] but in our part where tuberculosis is still endemic, 8 cases were found, in most of which primary ileostomy was done because of active lesions at time of presentation. Traumatic perforation is on rising trend as in other study [7], we too operated 14 such cases, in which resection anastomosis in cases of multiple perforation or simple closure in single perforation . Nonspecific inflammation was the other predominant cause, in which no cause could be found and they were labelled as idiopathic cause. Late presentation, delay in operation ( $>48 \mathrm{hrs}$ ), multiple perforations, gross contaminations of the peritoneal cavity with pus and faecal material and patients general condition affected surgical procedures, postoperative complications and subsequent morbidity and mortality[8,9,10,11]. The peritoneal fluid content and delay in surgical time increases the severity of contamination and friability of the bowel.

In our study, Simple closure in two layers was done in young patients presenting early usually $24 \mathrm{hrs}$ with no physical features of toxicity and any peritoneal contamination and single perforation. Patients who presented even late, but general condition was good, simple closure was done. Resection and anastomosis was practiced in patients with good general condition having multiple perforations or large perforation, having minimal peritoneal contamination. Simple closure with defunctioning loop ileostomy was mainly done in patients presenting late, with features of toxaemia and peritoneal contamination and who can't survive another major surgeries in near future. Site of perforation, terminal ileum close to IC junction, was instrumental in undergoing the procedure. Primary ileostomy was carried out in majority, 34, of the patients because of the late presentation, features of toxaemia, peritoneal contamination and most importantly patients' poor general condition.

\section{Conclusion}

RIMS (RajendraInstitute of Medical Sciences), is a centre of excellence in Jharkhand catering services to patients from Jharkhand, adjoining areas of Bihar,West Bengal, Chhattisgarh and Orissa. Patients from these regions mostly belong to low socio economic background, and are nutritionally challenged. Ignorance of health and lack of health education due to difficult access in these areas are significant issues.

The surgical procedure(s) thus should be considered keeping in mind such issues, general condition of the patient, delay in hospitalisation and time since presentation and operative findings which all have considerable influence on morbidity and mortality of the patient. In this observational study primary ileostomy was found to be the most optimal surgical technique.

Table 1: Causes of perforation:

\begin{tabular}{|c|c|c|}
\hline Causes of perforation & No. of cases & Percentage \\
\hline Typhoid & 42 & 60 \\
\hline Traumatic & 14 & 20 \\
\hline Tuberculosis & 8 & 13 \\
\hline Idiopathic & 6 & 7 \\
\hline
\end{tabular}

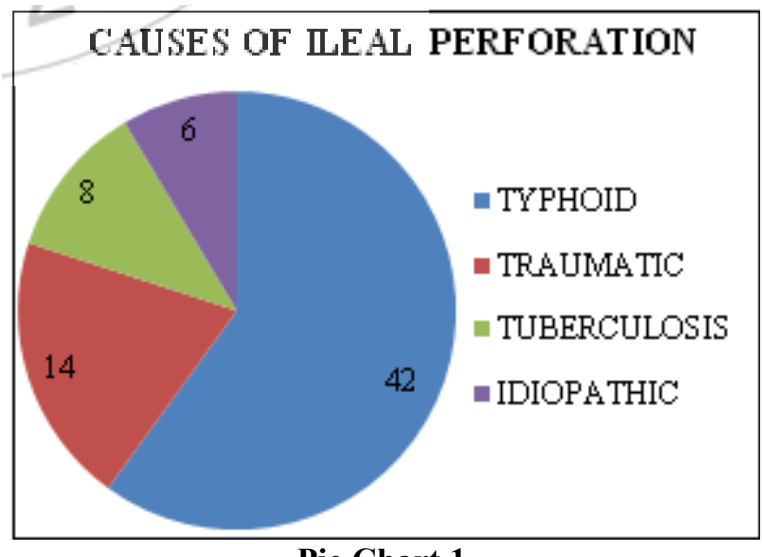

Pie Chart 1 
International Journal of Science and Research (IJSR)

ISSN (Online): 2319-7064

Index Copernicus Value (2015): 78.96 | Impact Factor (2015): 6.391

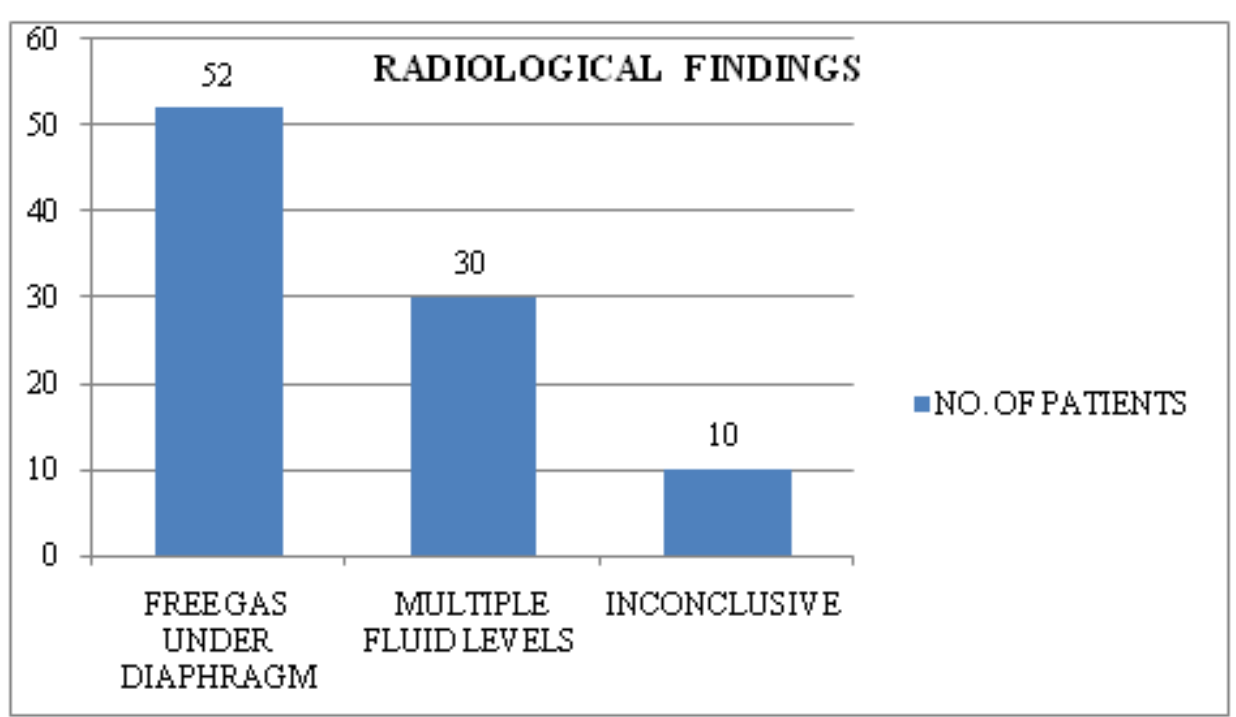

\section{Bar Graph 1}

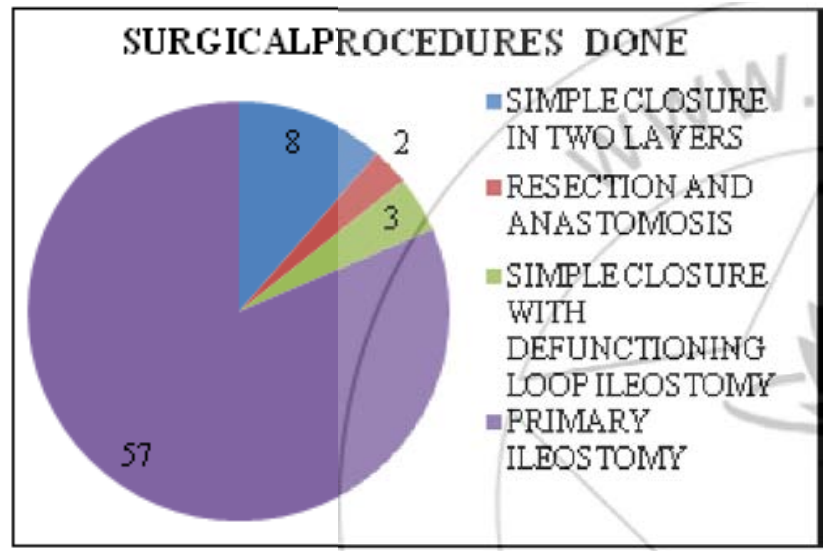

Pie Chart 2:

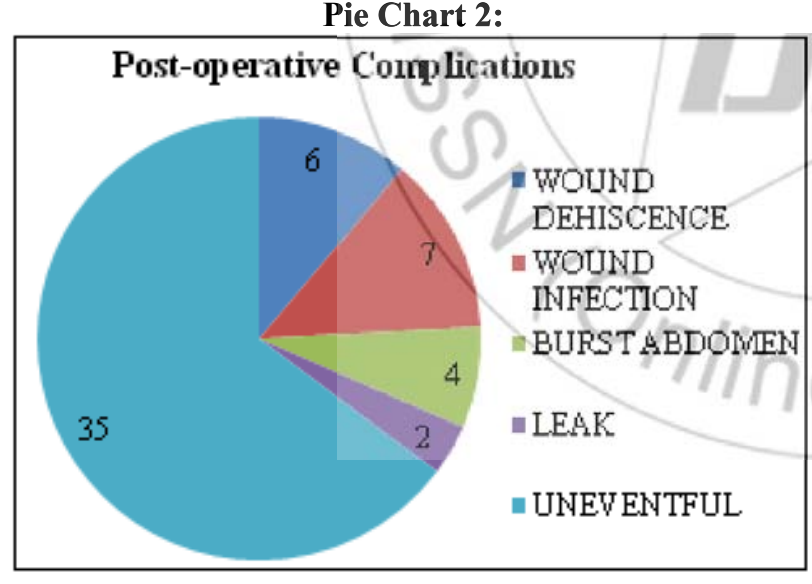

Pie Chart3

Pie Chart3
Table 2: Post-operative Complications

\begin{tabular}{|c|c|c|c|c|c|}
\hline $\begin{array}{c}\text { Procedure } \\
\text { Complications }\end{array}$ & $\begin{array}{l}\text { Primary } \\
\text { Ileostomy }\end{array}$ & $\begin{array}{l}\text { Simple } \\
\text { Closure }\end{array}$ & $\begin{array}{c}\text { Simple } \\
\text { Closure With } \\
\text { Defunctional } \\
\text { Ileostomy }\end{array}$ & $\begin{array}{l}\text { Resection and } \\
\text { Anastomosis }\end{array}$ & \\
\hline Uneventful & 48 & 4 & 1 & 1 & 54 \\
\hline $\begin{array}{c}\text { Surgical Site } \\
\text { Infection }\end{array}$ & 3 & 0 & 0 & 1 & 4 \\
\hline $\begin{array}{c}\text { Wound } \\
\text { Dehiscence }\end{array}$ & 1 & 2 & 1 & 0 & 4 \\
\hline $\begin{array}{c}\text { Burst } \\
\text { Abdomen }\end{array}$ & 2 & 0 & 1 & 0 & 3 \\
\hline \multirow[t]{2}{*}{ Leak } & 3 & 2 & 0 & 0 & 5 \\
\hline & 57 & 8 & 3 & 2 & \\
\hline
\end{tabular}

Volume 6 Issue 1, January 2017

www.ijsr.net 


\section{International Journal of Science and Research (IJSR) \\ ISSN (Online): 2319-7064}

Index Copernicus Value (2015): 78.96 | Impact Factor (2015): 6.391

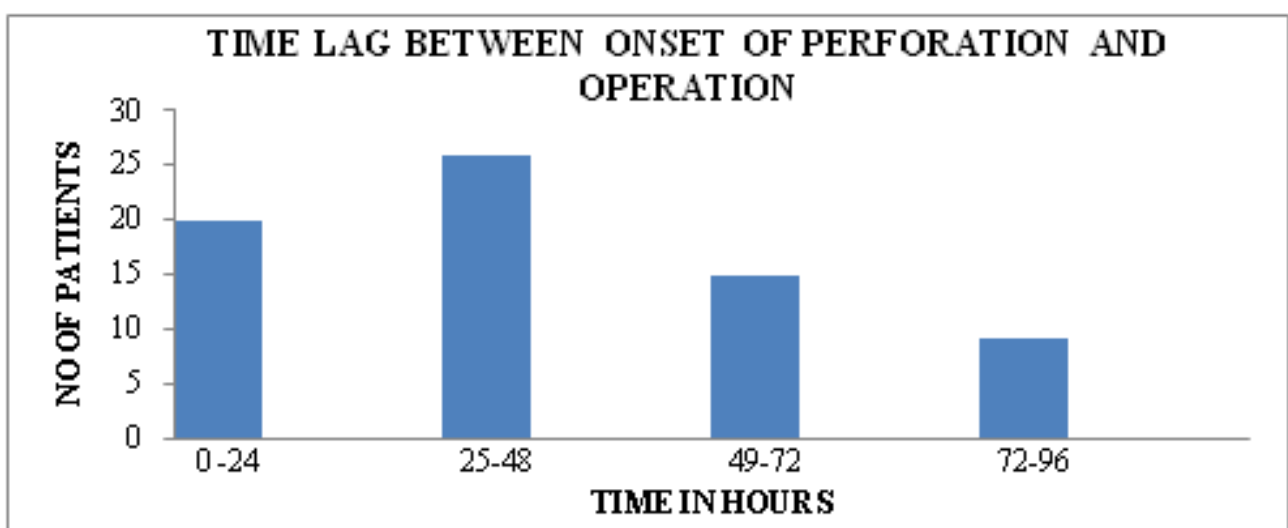

Bar Graph 2:

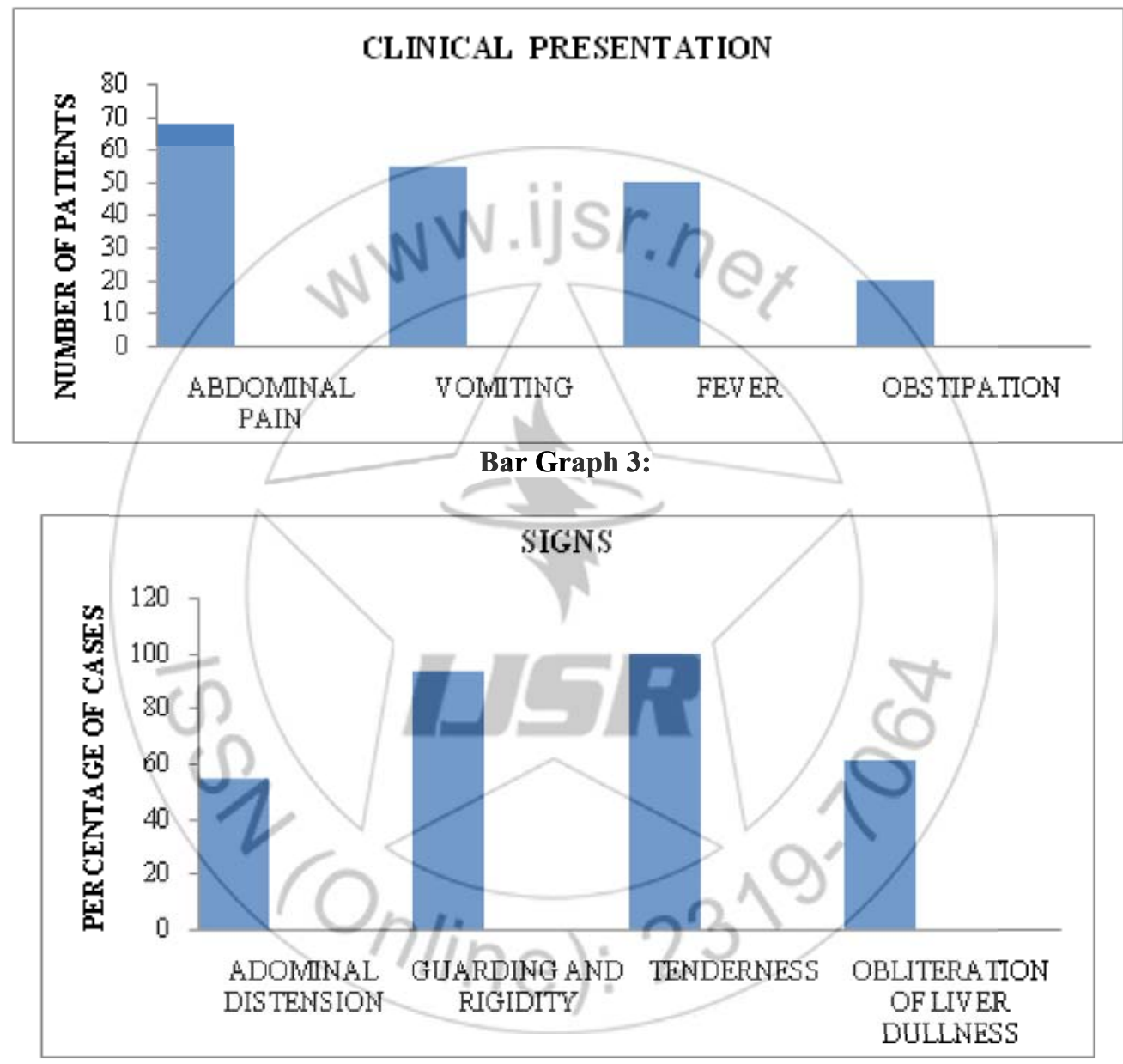

Bar Graph 4

\section{References}

[1] Egglestion FC: Santoshi B: Typhoid perforation: choice of operations. Br.J. Surg 1981, 68: 341-342

[2] Background document: The diagnosis, treatment and prevention of typhoid fever. Communicable disease surveillance and response.Vaccines and biological.WHO/V\& B/03-07

[3] Swadia ND, Trivedi PM, Thakkar AM, The problem of enteric ileal perforation, Indian journal of surgery 1979;41:643-651

[4] Keenan JP, Hadley GP, Surgical management of typhoid perforation in children Br. J. Surgery1984;71(12):928
[5] Santillana M. Surgical complication of typhoid fever; enteric perforation. World J Surg1991; 15(2):170-5

[6] Cocculini F, et al, tubercular bowel perforation:ulustravmaacilcerrahi derg.2011 jan;17(1):66-74

[7] G. kishore Babu1 et al, a clinical study on ileal perforation. JEBMH,2016:21(3):876-881

[8] Adesunkani AR, et al. The prognostic factors in typhoid ileal perforations: a prospective study of 50 patients. J R CollSurgEdinb. 1997 Dec;42(6):395-9

[9] Vander Werf TS, et al,typhoid perforation of ileum: a review of 59 cases seen at Agogo hospital , Ghana between 1982- 1987. Trop Geogr med 1990;42:360-6

[10] Chanh NQ, Everest P, et al, a clinical , microbiological and pathological study of intestinal perforation 


\section{International Journal of Science and Research (IJSR) \\ ISSN (Online): 2319-7064}

Index Copernicus Value (2015): 78.96 | Impact Factor (2015): 6.391

associated with typhoid fever. Clinical infectious diseases 2004;9:61-7

[11] Parades C, et al,: prognostic factors in typhoid

perforation. Rev gastroenterol/ peru 1993,13(1):13-19 